\title{
A SPECIMEN OF MELANOPLUS DIFFERENTIALIS THOMAS WITH FOUR OCELLI ${ }^{1}$
}

\author{
Robert D. Glasgow \\ University of Illinois.
}

For some reason contributions to the literature of teratology from insect examples have been made in far greater numbers by European entomologists than by their American colleagues, yet there seems to be no apparent reason why abnormalities should be proportionately rarer among American insects or in the materials handled by American students of entomology. The writer has himself encountered no less than six interesting examples of arthropodan malformations in the course of his work, and every entomologist who has examined carefully any considerable amount of insect material must have observed some specimens which presented noteworthy abnormalities that should be recorded in the literature of biology, and thus made available for consideration by investigators who may have a special interest in these phenomena.

From the nature of these phenomena the occurrence of examples must be sporadic, and since each case standing alone may seem to the observer to have little signficance, they are likely to be unheeded, or at least unrecorded, and consequently lost to science. It is probable also that many examples of insect abnomalities have never been reported because the observers have hesitated simply to describe them without comment, and have not felt prepared to supplement their presentation with a plausible explanation or interpretation.

Not only is an interpretation not necessary in reporting examples of such malformations of insects, or of other organisms, but indeed any attempt to formulate an interpretation of such phenomena is scarcely warranted, unless the observer has studied a considerable body of data accumulated from many similar or related cases. It is sufficient simply to place each example on

${ }^{1}$ Contribution from the Entomological Laboratories of the University of Illinois, Number 92.

(Read at the Cincinnati meeting of the Entomological Society of America, December 27, 1924.) 
record as it comes to the attention of the observer, by publishing a good description, accompanied by a figure if possible, and by stating where the specimen has been deposited. It may well be considered a duty to do this much, since it must be largely from such reports of sporadic cases that data and materials may be assembled for consideration by those who may wish to make intensive studies of teratology to supplement experimental data to which it may be pertinent. Moreover, every case of insect abnormality should be reported however commonly the particular type of malformation may have been reported before; for the multiplication of examples of any one type of variation may well be as important as reporting unique examples of entirely new types.

Among the various examples of insect malformation encountered by the writer, one of the most interesting is a specimen of the common short-horned grasshopper, Melanoplus differentialis. This specimen, which seems to be normal in every other respect, has four ocelli instead of the three which are normal for this species. In this specimen the lateral ocelli are normal in position, in form, and in size. The median ocellus, however, is represented by two perfectly formed ocelli which are disposed symmetrically, one on each side of, and laterad from the point where the normal median ocellus should be, and separated from each other by a distance somewhat greater than the diameter of a normal median ocellus.

Each of these para-median ocelli presents the characteristic oval form of a normal ocellus, each has a characteristically distinct, convex cornea, and each is situated in a separate characteristically oval depression in the front; but these aberrant ocelli are somewhat smaller than normal, so that the two ocelli together would present an aggregate area but little if at all greater than the area of a normal median ocellus.

The individual presenting this abnormality was found ${ }^{2}$ in a lot of several hundred specimens which had been preserved for

${ }^{2}$ The attention of the writer was first directed to the anomalous condition of the ocelli in this specimen by a student in the introductory course in general entomology, Miss Margaret Windsor, who protested that the specimen given her for study did not agree with the specifications in the laboratory outline. 
the study of external anatomy, and which were of uncertain origin. Because of the lack of suitable preservation, no attempt was made to study the structure of the median ocellar nerve. Instead, the specimen was preserved intact, and will be placed in the type series of the insect collections at the University of Illinois, where it can be studied further by anyone to whose work such a study may be relevant.

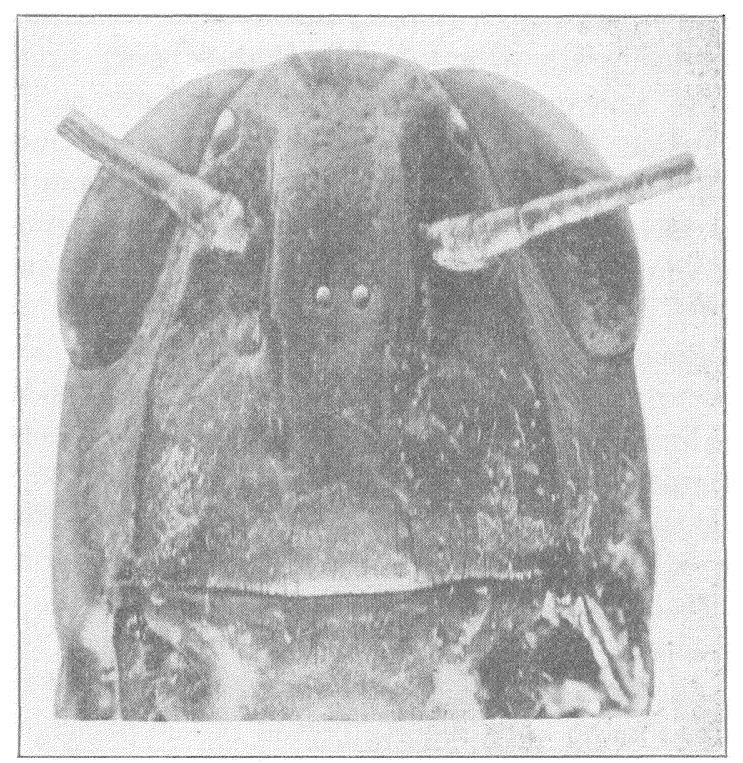

Fig. 1. Melanoplus differentialis with four ocelli, anterior view of head.

This particular malformation appears to be exceedingly rare among insects. The only other examples known to the writer are a specimen of the common meadow grasshopper, Melanoplus femur-rubrum Riley, described by M. W. Blackman, ${ }^{3}$ and a specimen of a saw-fly, Tenthredella simirubra Norton, described by M. T. Smulyan. ${ }^{4}$ In Blackman's specimen the median ocellus was replaced by a second pair of ocelli in a manner almost identical with the example here reported.

${ }^{3}$ Blackman, M. W., Psyche, v. I9, I912, pp. 92-96, I fig.

${ }^{4}$ Smulyan, M. T., Proc. Bost. Soc. Nat. Hist., v. 36, 1923, p. 401. 
The first hypothesis to suggest itself, and one that has already been advanced to explain this type of malformation, is that it may have a phylogenetic significance, and may constitute a reversion to an ancestral condition.

Examining the plausibility of this hypothesis, we find that Patten $^{5}$ has shown in a late larval or prepupal stage of a wasp, that the median ocellus first appears as a pair of separate pits or vescicles, which later unite to form a single ocellus on the median line. Packard ${ }_{6}$ has stated that in the pupa of a bumble bee the median ocellus presents a "double shape, being broad, transversely ovate, and not round like the two others, as if resulting from the fusion of what were originally two distinct ocelli."

Ieydig, ${ }^{7}$ Rabl-Rueckhard, ${ }^{8}$ Carriere, ${ }^{9}$ Viallanes, ${ }^{10}$ Janet, ${ }^{11}$ and others have shown that in certain adult Hymenoptera the median ocellar nerve is double throughout some part of its length, while Burgess ${ }^{12}$ in his figure of the brain of the Rocky Mountain Locust shows the median ocellar nerve to be unpaired in that species; still, in common with all structures located on the middle line of an organism having bilateral symmetry, where in early segmentation stages the plane of one of the cleavages corresponds to the future middle line, the median ocellus must in all groups of insects have been double at some point in the course of its development in the individual, and the condition of this structure in the Hymenoptera might seem to indicate that its origin from the fusion of an ancestral pair of ocelli may have occurred at no very remote period in the phylogeny of the class.

Indeed, the hypothesis begins to look delightfully plausible when only the supporting evidence is considered, but on the other hand it is well known that organisms tend to vary in all

${ }^{5}$ Patten, W., Journal of Morphology, Boston, v. I, I887, pp. 193-226. 'Packard, A. S., Text Book of Entomology, I 898, p. 250.

${ }^{7}$ Leydig, F., Tafeln zur vergleichenden Anatomie, Tubingen, 1864, Figs. 3-4.

${ }^{8}$ Rabl-Rueckhard, Archiv. f. Anat., Physiol., und Wiss-Medicin, 1875, pp. 480-499, pl. XIV.

${ }^{9}$ Carriere, J., Die Sehorgane der Thiere, Muenchen und Leipzig, I885.

${ }^{10}$ Viallanes, H., Ann. Sci. Nat. Zool. I887, 7 Ser. II, pp. 5-IOo, 6 plates.

${ }^{11}$ Janet, Chas., Anatomie de la Tête du Lasius niger, Limoges, 1905, 40 pages, 5 plates.

${ }^{12}$ Burgess, E., 2nd Report, U. S. Ent. Comm., I880, pp. 223-242, pl. IX. 
directions from the type. In organisms having bilateral symmetry where either paired structures, or the two halves of unpaired structures standing on the middle line, are geometrically related to each other as optical images with reference to the meson or axis of major symmetry, meristic variation in such a bilateral series may take either one of two directions. Bilaterally paired structures may be placed farther apart, or they may be brought closer together; and in the latter direction the degree of variation may extend to their becoming united to form a single median structure or even to their complete suppression. Normally unpaired, median structures may on the one hand be divided into two, so as to form a pair of bilaterally symmetrical structures, while on the other hand they may be reduced in size or entirely lost.

Indeed, it contrasts with the variation resulting in the division of the median ocellus, examples are also available to illustrate meristic variation of the same bilaterally symmetrical series fo structures in the direction of fusion, and even to the point of complete suppression.

Stannius ${ }^{13}$ reported a worker honey bee specimen in which there is a complete fusion of the two compound eyes into a single symmetrical, elongate compound eye, that is uniformly continuous across the middle line. In this specimen there is also a reduction from the three ocelli which are typical for this insect, to a single ocellus located on the dorso-meson. Lucas ${ }^{14}$ reported the similar fusion of the compound eyes in a honey bee of doubtful caste, accompanied by the complete suppression of the ocelli.

The median union of the ocelli could scarcely be interpreted as a reversion to an ancestral condition, and certainly the two opposite variations exhibited by these structures could not both be so interpreted. What may be the causes leading to either of these discontinuous changes we do not know; but it is not unlikely that variation in either direction may be found to result from the operation of the same factor or group of factors. At least it is better to refrain from drawing superficially plausible conclusions until we know more of the directive mechanism which

${ }^{13}$ Stannius, Mueller's Archiv. f. Anat: u. Physiol., I835, P. 297. Pl.

${ }^{14}$ Lucas, H., Ann. Soc. Ent. France, I 868 , ser. 4, v. VIII, p. 737, Pl. 
molds the developing organism so uniformly true to type, and of the condition which now and then may cause the development of an individual in some detail to halt a little short of, to over-run, or otherwise to deviate from its due course.

It is truly an obligation, very generally neglected by American entomologists however, to record each example of insect teratology simply and directly, just as it is observed; but the fulfilment of this obligation is by no means accompanied by any additional obligation to offer at the same time an explanation or interpretation of the phenomenon. Indeed, in the present state of our knowledge of such phenomena any attempt to interpret individual examples is rarely demanded, or even scientifically justifiable.

\title{
THE SECOND ABDOMINAL PLEURITE IN THE HIGHFR COLEOPTERA
}

\author{
By W. T. M. Forbes, \\ Cornell University, Ithaca, New York.
}

It is generally recognized that the first sternite of the abdomen is membranous in all the holometabolous insects. As to the first pleurite and the second segment there takes place a gradual reduction, which reaches such a stage that in the majority of Coleoptera the first two segments are represented by a more or less membranous dorsal and spiracular region only.

The usual statement is that the first segment of the abdomen has atrophied, and that the second is ventrally absent and laterally fused with the third. An examination of fresh specimens shows that this is not strictly the case. In fact the second pleurite may disappear in at least two different ways.

In the Bostrychiformia (Fig. 1, A) the first stage seems to have been an infolding of the whole subspiracular region of the first two segments, so that the hind coxa comes to lie against the anterior edge of the third segment or even overlap it somewhat. In this way the two segments are completely buried from view, and their sclerites become more or less completely de- 

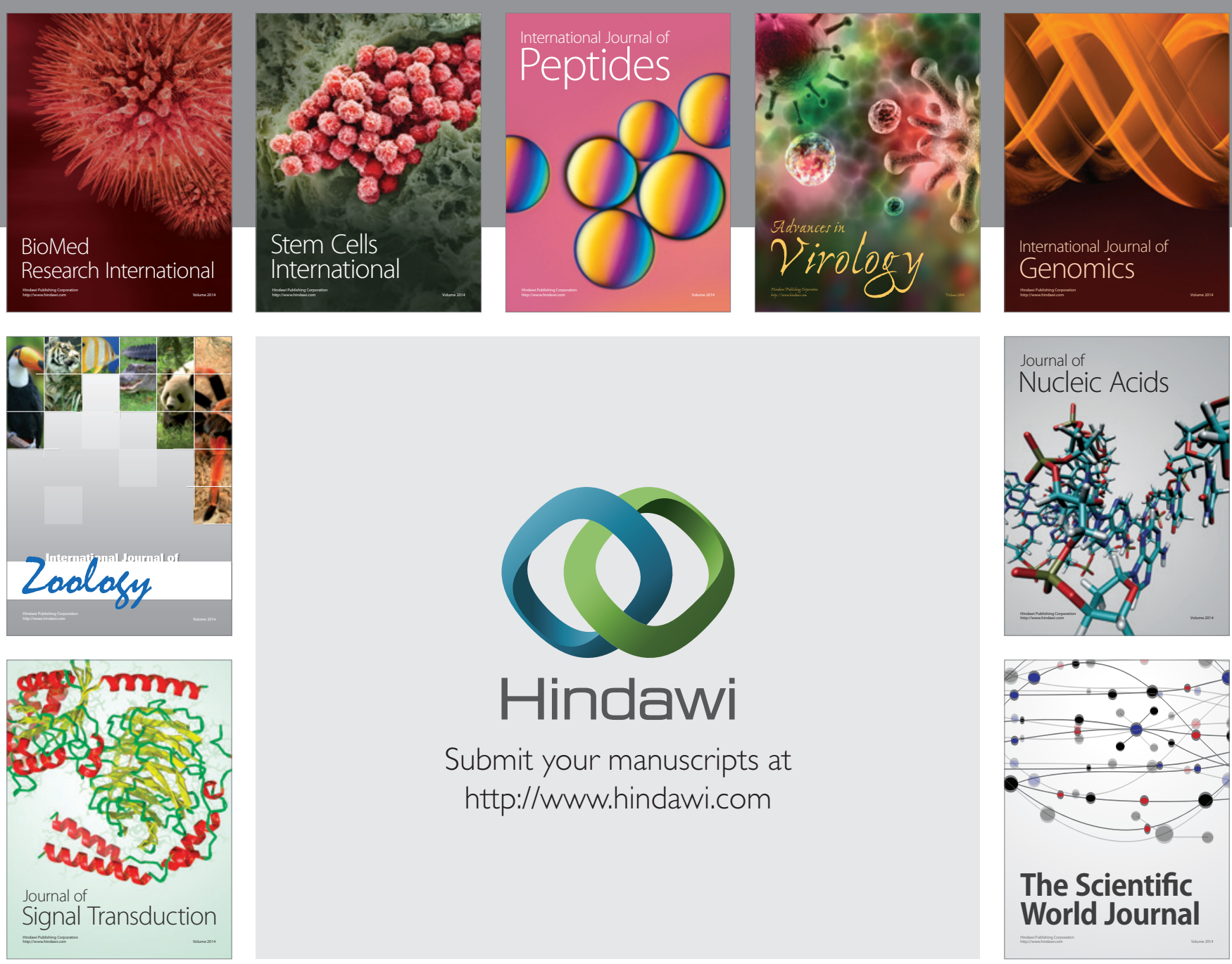

Submit your manuscripts at

http://www.hindawi.com
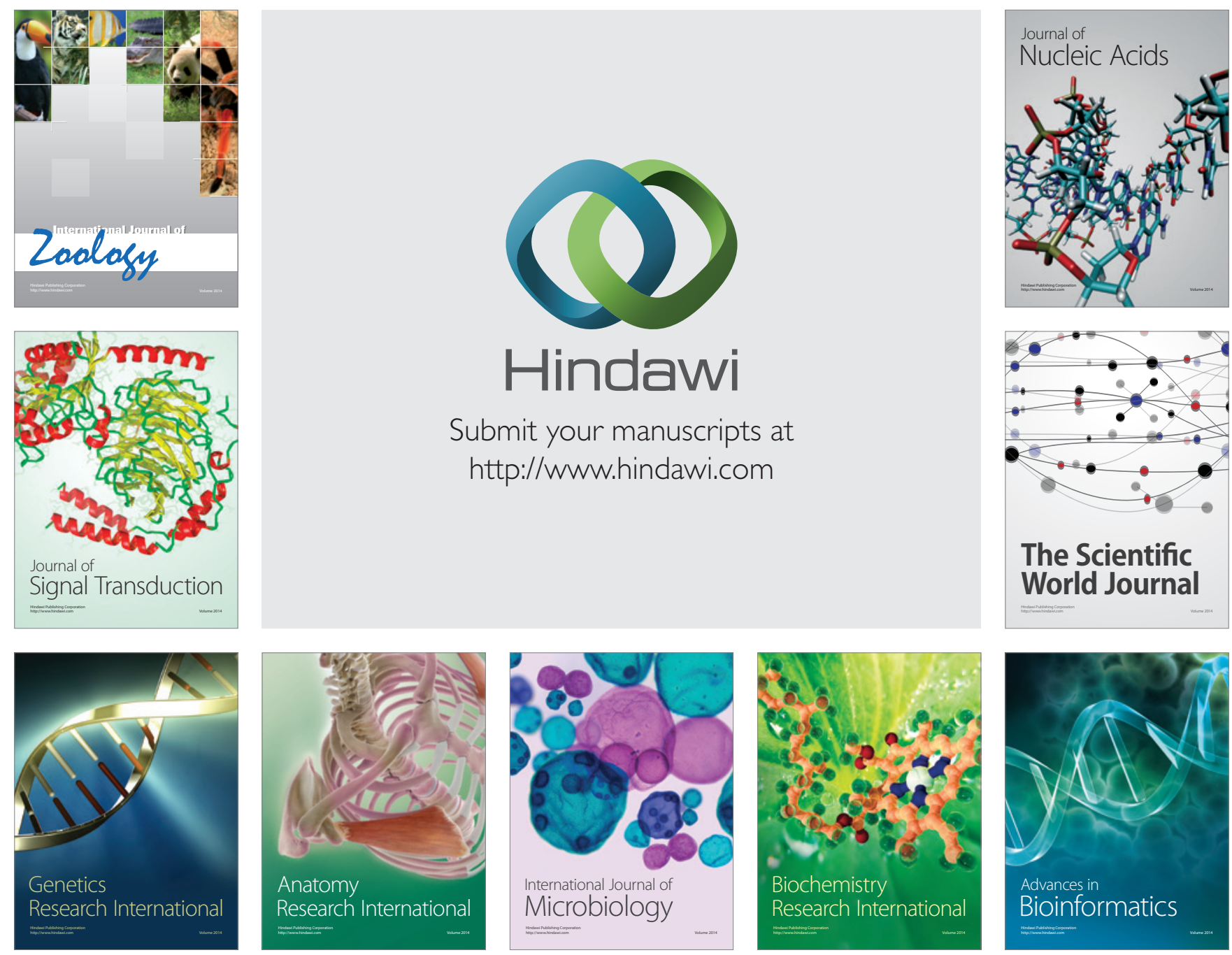

The Scientific World Journal
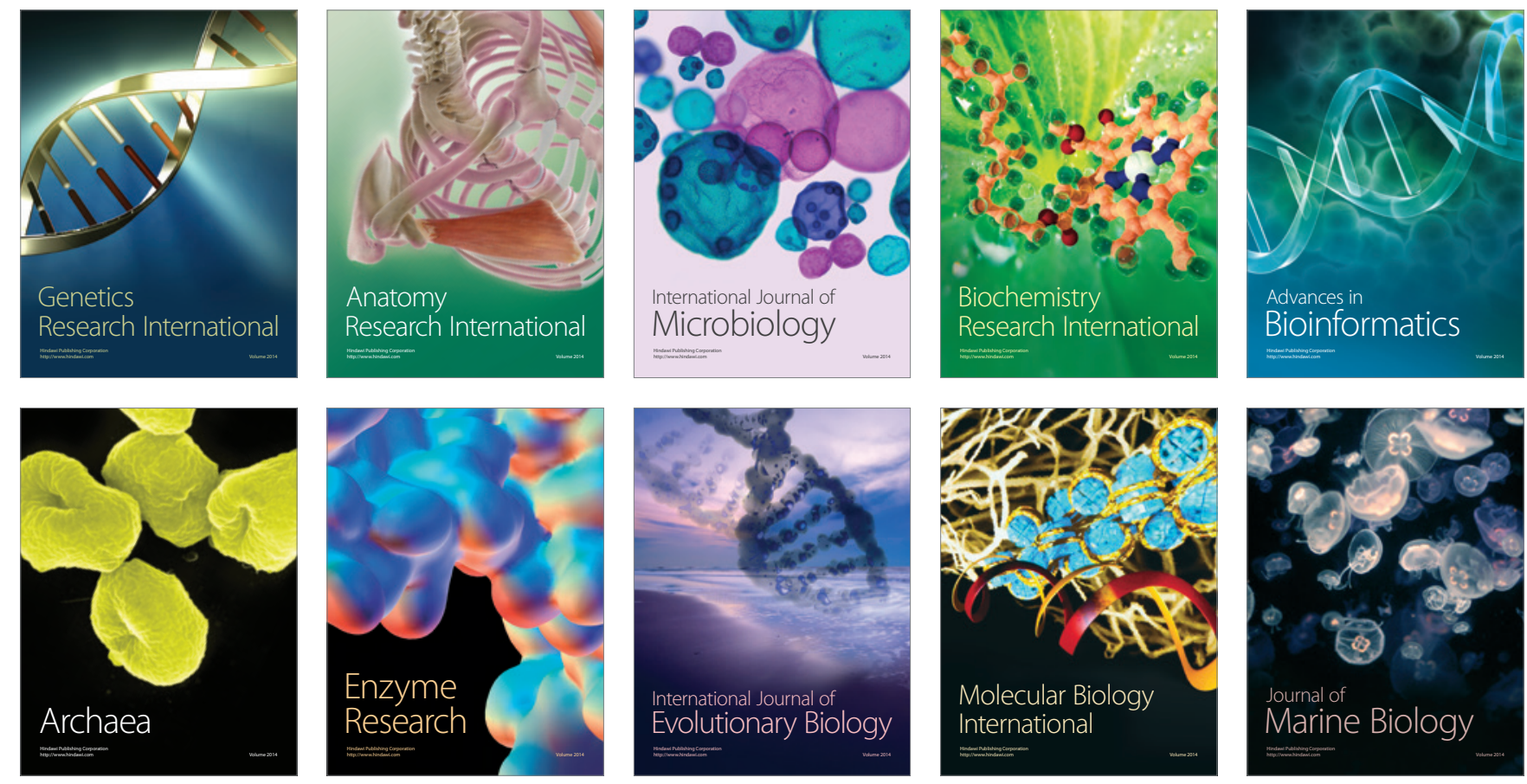